\title{
The Carrier Study of College Students' Ideological and Political Education in 4G Context
}

\author{
Zhanxia Wang \\ Zhejiang Vocational Academy of Art \\ Hangzhou, 310053, China
}

\begin{abstract}
Under mobile media environment, college students' ideological and political education is currently facing the opportunities and challenges. The use of 4G technologies has been popular among college students, and 4G technologies have begun promoted. With a wireless network escalating the university campus, students can enjoy the fun with the media on campus every corner. Mobile media is producing more and more profound impact on college students' learning styles, lifestyles, ways of thinking and behavior, which for the work of college students' ideological and political education is not only a precious opportunity, but also a real challenge.
\end{abstract} Network

Keywords- mobile phones; ideological and political education;

\section{VALUABLE OPPORTUNITY OF IDEOLOGICAL AND POLITICAL EDUCATION UNDER A MOBILE MEDIA ENVIRONMENT}

\section{A. Resource of ideological and political education is richer}

The vitality of Mobile Media is connection to the Internet. The fusion of mobile media and network media expands the variety of new information and communication methods, such as mobile search, mobile websites, mobile micro-blog, and mobile instant messaging and so on, which greatly expands the coverage of information dissemination. With the development and upgrading of mobile communications technology, mobile media will develop and refine more areas to make it truly become a "mobile computer".

Major domestic media recognizes the strong vitality of mobile media and tries to seize new positions of Mobile media. The countries mainstream media, like 2005 People's Daily, Xinhua have started its own mobile site. Among them, the Xinhua launched the first Xinhua global alert in "Pocket World" website, Xinhua pictures, at the same time the Xinhua launched a mobile Xinhua net based on mobile browser. Meanwhile, the Guangming Daily, China Youth Daily and other national dailies which also have a significant impact are on the official Internet.

With the development of data communications and multimedia business needs, the fourth generation mobile communication begins to rise to adapt mobile data, mobile computing and mobile multimedia operational needs. So it is reasonable to expect that this fourth-generation mobile communications technology will bring better future. On the other hand, because of its ultra-high-speed data transmission, 4G has also been regarded as "high-speed dialogue" between machines by schools and enterprises of China Things alliance.

Under the promoting of emerging communications technologies, WCDMA, which symbolizes 4G communication technology, has become a mainstream of communication technologies. The technology can provide users with the highest $2 \mathrm{Mbit} / \mathrm{s}$ data transfer rate. In such conditions, any media computer applications can easily be passed through the wireless network. With the effective help of wide band, WCDMA can not only handle voice and image data smoothly, but also quickly connect to the Internet; in addition, the fusion of WCDMA and MPEG-4 technology can handle real dynamic images.

\section{B. $4 G$ technology enhances the effectiveness of ideological and political education}

Freedom and openness of 4G networks allow educators and learners to have equal status and rights of access to information, which further promotes the students to establish the concept of modern information. It pays more attention to equal exchange and real-time interaction, largely playing its own initiative, which changes the traditional way of communication mode transmission, effectively mobilizing their enthusiasm after the college students gain first-hand information and actively involved in the study and discussion of the ideological and political education. The new media under $4 \mathrm{G}$ can change the management system of ideological and political education. The network will become an important field of practice of ideological and political education, so as to enhance the effectiveness of ideological and political education.

\section{Mobile media brings challenge for the college students' ideological and political education}

As a borderless, openness media tools, information passed by mobile new media is vast. The undeniable thing is that ideological and political education provides a wealth of information, which develops the vision of college students, and enriches the spare life of college students. However, this random dissemination of information makes students easily get rid of moral constraints of the real world, easily indulge their behavior, forget social responsibility, at the same time that information without the clutter and screening, can easily lead to university students lost ideals and beliefs, which will influence their ideals, beliefs and values. 


\section{The immune system of mobile media's adverse effects for students should be improved.}

In today's society, bad information is pervasive, affecting young college students all the time. Thus, on the one hand we should strengthen the ideal and faith education for college students,constantly improving the ideological and political quality of college students, so that students correctly understand the laws of social development, recognize the future destiny of the country and their social responsibility; on the other hand, we should cultivate college students mobile media moral qualities, and Students' sound personality and noble sentiments, prompting the formation of the correct value judgments and noble aesthetic taste, consciously resisting the erosion of harmful information, relying on young college students own inner strength to digest negative impact of mobile media. Also, we should help students overcome various psychological problems caused by the mobile media through a variety of educational activities.

\section{INTERNET CULTURE IS THE NEW REQUIREMENT OF THE TIMES FOR THE IDEOLOGICAL AND POLITICAL EDUCATION.}

Contemporary college students have ideological emancipation and active thinking. Internet culture, as an important part of campus culture, greatly updates college students' concepts and ideas, stimulates innovation consciousness and the sense of competition of college students. Internet culture belongs to the new things which college students are willing to accept, which to some extent has laid a good foundation for the new era of ideological and political work of college students. Therefore, the content, forms and methods of the ideological and political education should take the initiative to adapt to students' ideological and cultural actual network environment, keep innovating, and always maintain the quality of the times. The traditional form of ideological and political education work of college students is no more than report, lectures, debates, class meetings, study tours, cultural activities on campus as well as a variety of entertaining social practice.

Internet is "the fourth media" in today's society, the construction and use of the network position is the new issue to carry out ideological and political education. Internet is called the "fourth media" because the network runs away from time, space, geographical constraints, so the range of ideological and political education is broad [5]. We can use the characteristics of the Internet to establish the ideological and political education network, to discover and solve problems, making the Internet a new ideological and political education advocacy positions. Currently, many colleges use the campus network for the ideological and political education, establish the era of ideological and political education website combined with the characteristics, making the network really as I use, making use of the correct guidance of public opinion, advanced mainstream culture which has brought good results.

\section{THE DIFFICULTY OF IDEOLOGICAL AND POLITICAL EDUCATION INCREASES}

The information dissemination of mobile media goes into the "No barrier" 、 "Space without barriers" Time, which provides a wealth of educational resources and vast educational space for ideological and political education. But due to the fact that the current development of mobile media just begins for a short time, relevant laws and regulations are still unsound, the relevant departments are not perfect, so that mobile media enters into the "information barrier-free" era. The mobile media information is spread unevenly, bringing the influx of a large number of non-ethical, false bad information, filled with a lot of information which has a reactionary, pornographic, feudal color.

Currently, mobile media has become an essential interpersonal tool. That adverse information can easily enter the daily lives of college students, which has a serious impact on the value orientation and moral awareness of college students. College is an important stage of growth and transition phase in one's life, where students ideology is not yet mature, mainly shown by the not firm enough moral beliefs, relatively weak political sensitivity, lacking selfcontrol and identifying ability. So, faced with huge information resources passed by mobile media, many students are likely to lose the ability to identify, difficult to make exactly right judgments, and thus can not effectively resist the erosion of the bad information and bad thinking.

Exploring the method and means to make the ideological and political education scientific and refined under the background of the new media shows the penetration of ideological and political education. New media technologies has many advantages, such as large amount of information, rich resources, convenient transport, without time and space constraints and so on, which greatly expands the spatial ideological and political education, and actively builds a new platform for ideological and political education. New media has a clear advantage in this regard. As for the means of education, it uses forums, message boards, QQ group and other tools to carry out online exchanges and online psychological testing and counseling, online employment guidance work, timely solving the practical problems reflected by Students on learning, friends, and employment. The way of a single, double, multi-directional interaction, not only helps ideological and political educators and college students engage in dialogue to talk, can also explore the theory by convening small classes.

\section{IMPROVING COLLEGE STUDENTS' ABILITY TO DISTINGUISH THE NETWORK INFORMATION}

To strengthen the positive guidance, harmful information should be processed according to the law and the erroneous statements should be actively carried out by public opinion guidance, the users language should be used to guide work patiently and meticulously. Channels of information dissemination under new media must be strictly supervised and managed. As colleges do not have the technical conditions and management conditions of supervision to 
mobile news and other forms of new media, bad information from off-campus can not be monitored, and colleges can not effectively control the dissemination of information, it is necessary to further improve the system of laws of the dissemination new medium information, improve the monitoring mechanism of new media publishing information, so that the information source is good. In addition, colleges should strengthen the early warning supervision by constructing virtual organizations a network, setting the network administrator. This warning also should take a combination of guidance and prevention strategies. It includes both establishing a scientific network ethics education and focusing on guiding students correctly understand computers and networks from the moral point, so as to improve college students' ability to distinguish the network information.

\section{THE IDEOLOGICAL AND POLITICAL EDUCATION OF COLLEGE STUDENTS UNDER 4G BACKGROUND}

From the point of view of traditional ideological and political education, educators influence the impact of the ideological and political education due to limitations of subjective and objective conditions, small reservation of information and knowledge, narrow coverage. Today, the Internet as a representative of the new media makes global information sharing possible. Ideological and political educators can collect the ideological and political education resources in different contexts from different regions through the network, and achieve strong interaction with convenient interactive network characteristics, thereby maximize the sharing of educational resources. Then the original narrow and closed universities ideological and political education space changes into a whole society, which makes the channel of ideological and political education smooth, and provides a very vivid and rich educational resource for the ideological and political education.

The inherent nature of oversized information of new media and information technology makes the content of education full and rich with selectivity and objectivity; second, "the new media technology makes educational content to the three-dimensional shape, dynamic, trend Macros." By this way, you can make the collectivism, patriotism, these ideological and political education materials difficult to grasp become lively, attractive through the collection sound, color, light, painting as one of the new media technologies deduced, greatly enhancing the ideological and political education. Currently, the speed of changing information is fast. With the help of new media, ideological and political educators can complete collection and screening of ideological and political education in a short time, selecting the ideological and political education with strong times and educational meaning, which greatly improves the timeliness of ideological and political education, reflects the work requirements of ideological and political education.

\section{CONCLUSIONS}

Development of mobile Internet has brought unprecedented challenges and opportunities to the college students' ideological and political education. On the one hand, the traditional ideological education work, methods, ideological and moral quality of educators, scientific and cultural qualities, the ability to handle modern information technology and the values and behaviors of college students are facing serious challenges. On the other hand, the mobile Internet, as an advanced, revolutionary scientific and technological strength, will continue to promote economic globalization and accelerate the transformation of development of human society, which opens a new space and creates a new channel for the launch of the ideological and political education work. Faced with the development opportunities and challenges under the new situation, we must change the traditional concept of ideological education, and create a new platform by the use of wireless network, for strengthening the cultivation of college students professional team, and innovative ways and means of ideological and political education, strengthening the construction of the mobile Internet, improving the management system, and strengthening the mobile Internet censorship, so as to clean network environment. With $4 \mathrm{G}$ technology, to create a new platform for mobile network ideological and political education, in theory, users can access the wireless network access technology fixed network resources, but that does not mean we can change the existing network with ideological and political education outcomes copied directly to the mobile Internet. It should work based on the mobile Internet features. To the characteristics of mobile networks, strengthen the transformation and information integration on ideological and political education site, which built wireless theme website.

\section{References}

[1] Bi Ran Innovation and Development of Network Culture ideological and political education [J]. Radio and TV University, 2008, 02: 70-73 +99 .

[2] Huang Jingang goals and approaches on Ideological and Political Education under the Harmonious Society [J]. Xiangtan Normal University (Social Sciences), 2008, 02: 22-25.

[3] Huang booming dominant ideological and political education of college students microblogging background $[\mathrm{J}]$. Tianshui Normal University, 2012, 05: 137-140.

[4] Ding Huimin guiding force in the new media context of the ideological and political education research $[\mathrm{J}]$. school party building and ideological education, 2010, 08: 45-46.

[5] Under Rui multicultural background of ideological and political education status quo and Construction [D]. Southwestern University, 2013.

[6] Chen Lin Ideological and Political Education of College Students under the Network Culture $[\mathrm{J}]$. Jinling Institute of Technology (Social Sciences), 2006, 04: 92-94 + 101. 